\title{
Imaging findings in faciobrachial dystonic seizures associated with LGI-1 antibodies
}

Achados de imagem em crises distônicas braquiofaciais associadas à anticorpos anti-LGI-1

Ronnyson Susano Grativvol', Mateus Mistieri Simabukuro', Raphael Ribeiro Spera', Wagner Cid Palmeira Cavalcante1, Hugo Henrique Soares Araújo', Daniel Sakuno², Leandro Tavares Lucato², Lécio Figueira Pinto', Luiz Henrique Martins Castro', Ricardo Nitrini ${ }^{1}$

A 76-year-old woman presented with a three-month history of faciobrachial dystonic seizures associated with cognitive impairment and hyponatremia. Cerebrospinal fluid analysis was unremarkable. A whole-body CT scan demonstrated no malignancies. Brain MRI revealed involvement of the mesial right temporal lobe, right striatum and globus pallidus and bilateral supratentorial white matter (Figures A, B, C). Leucine-rich glioma inactivated protein 1 (LGI-1) antibodies were detected in the serum. The patient received immunosuppressive treatment, with a partial response. LGI-1 encephalitis is an immune-mediated encephalitis characterized by cognitive impairment associated with faciobrachial dystonic seizures and hyponatremia ${ }^{1}$. Neuroimaging findings include mesial temporal lobes, basal ganglia and supratentorial white matter abnormalites ${ }^{2,3}$.
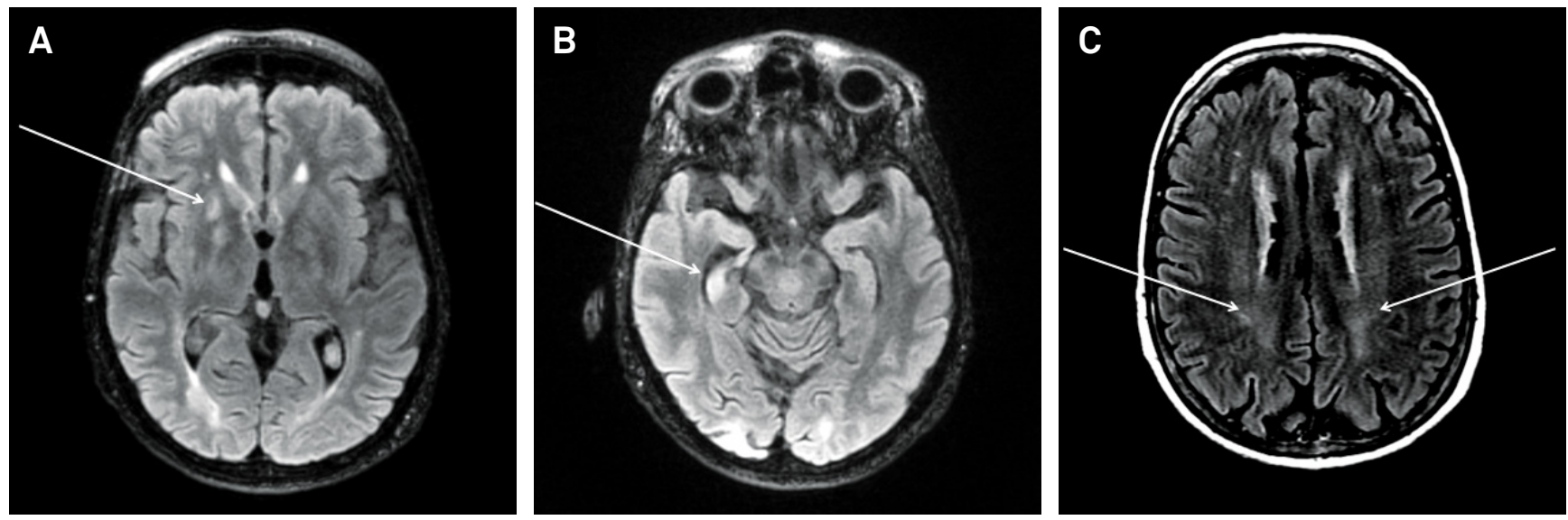

Figure. Fluid-attenuated inversion recovery (FLAIR) images (A-C) disclosed increased signal in the right caudate and putamen (arrow in A); right hippocampus and amygdala (arrow in B); and slight blurring of the bilateral supratentorial white matter (arrows in C). A small remote vascular injury in the right occipital pole was also noticed, but considered unrelated to the case (images A-B).

\section{References}

1. Lancaster E, Martinez-Hernandez E, Dalmau J. Encephalitis and antibodies to synaptic and neuronal cell surface proteins. Neurology. 2011;77(2):179-89. doi:10.1212/WNL.0b013e318224afde

2. Plantone D, Renna R, Grossi D, Plantone F, lorio R. Teaching neuroimages: basal ganglial involvement in facio-brachial dystonic seizures associated with LGl1 antibodies. Neurology. 2013;80(17):e183-184. doi:10.1212/WNL.0b013e31828f17fa

3. Urbach H, Rauer S, Mader I, Paus S, Wagner J, Malter MP et al. Supratentorial white matter blurring associated with voltage-gated potassium channel-complex limbic encephalitis. Neuroradiology. 2015;57(12):1203-9. doi:10.1007/s00234-015-1581-x

\footnotetext{
${ }^{1}$ Universidade de São Paulo, Faculdade de Medicina, Hospital das Clínicas, Departamento de Neurologia, São Paulo SP, Brasil; ${ }^{2}$ Universidade de São Paulo, Faculdade de Medicina, Hospital das Clínicas, Instituto de Radiologia, São Paulo SP, Brasil. Correspondence: Ronnyson Susano Grativvol; HCFMUSP; Departamento de Neurologia; Av. Dr. Enéas de Carvalho Aguiar, 255 / $5^{\circ}$ andar; $05403-001$, São Paulo SP, Brasil; E-mail: roninsg@hotmail.com Conflict of interest: There is no conflict of interest to declare. Received 19 July 2016; Accepted 10 August 2016
} 